DR. MARIO ROMANDINI (Orcid ID : 0000-0001-5646-083X)

MISS ZAMIRA KALEMAJ (Orcid ID : 0000-0002-2133-7505)

DR. ANDREINA LAFORÌ (Orcid ID : 0000-0001-5530-5280)

Article type : Systematic Review

\title{
Antibiotic Prophylaxis at Dental Implant Placement: Which is the Best Protocol? A Systematic Review and Network Meta-Analysis
}

Mario Romandini ${ }^{1-2-3}$, Ilaria De Tullio $^{1}$, Francesca Congedi ${ }^{1}$, Zamira Kalemaj ${ }^{5}$, Mattia D’Ambrosio $^{1-6}$, Andreina Laforí ${ }^{7}$, Ciro Quaranta ${ }^{1}$, Jacopo Buti $^{8}$, Giorgio Perfetti ${ }^{1}$

${ }^{1}$ Department of Medical, Oral and Biotechnological Sciences, University of Chieti- Pescara, Chieti, Italy.

${ }^{2}$ Institute of Dentistry and Maxillofacial Surgery, Fondazione Policlinico Universitario A. Gemelli IRCCS, Catholic University of the Sacred Heart, Rome, Italy.

${ }^{3}$ Currently undertaking the EFP Program in Periodontology at Complutense University, Madrid, Spain.

${ }^{5}$ Private Practice, Milan, Italy.

${ }^{6}$ Unit of Oral and Maxillofacial Surgery, Department of Biomedical and Neuromotor Sciences, University of Bologna, Bologna, Italy.

${ }^{7}$ Private Practice, Rome, Italy.

This article has been accepted for publication and undergone full peer review but has not been through the copyediting, typesetting, pagination and proofreading process, which may lead to differences between this version and the Version of Record. Please cite this article as doi: $10.1111 /$ jcpe. 13080

This article is protected by copyright. All rights reserved. 
${ }^{8}$ Unit of Periodontology, Eastman Dental Institute - University College London, London, UK.

Running title: Best Antibiotic for Implant Placement

Keywords: Antibiotic Prophylaxis; Implant Placement; Early Implant Failures; Early Failures; Implant Survival; Penicillins; Side Effects; Adverse Events; Systematic Review; Network Meta-Analysis.

\section{Correspondence address:}

Mario Romandini

Giovanni XXIII Square, 24

74123 Taranto

Italy

mario.romandini@gmail.com

$+393801563046$

\section{Conflict of Interest and Sources of Funding Statement}

The authors declare no conflicts of interest related to the contents of this study. This study was self-funded by the authors and their institutions, and no external funding was received.

This article is protected by copyright. All rights reserved. 


\begin{abstract}
Aim: This systematic review of randomized controlled trials (RCTs) aims to answer to the following question: "In patients undergoing dental implant placement, which is the best antibiotic prophylaxis protocol to prevent early failures?".
\end{abstract}

Materials and Methods: The MEDLINE, SCOPUS, CENTRAL and Web of Knowledge electronic databases were searched in duplicate for RCTs up to July 2017. Additional relevant literature was identified through 1) hand-searching on both relevant journals and on reference lists, and 2) searching in databases for grey literature. A Network Meta-analysis (NMA) was conducted and the probability that each protocol is the "Best" was estimated.

Results: Nine RCTs were included, with a total of 1,693 participants. Due to the few events reported, it was not possible to conduct a NMA for adverse events, therefore it was conducted only for implant failures (IF). The protocol with the highest probability (32.5\%) of being the "Best" one to prevent IF was the single dose of $3 \mathrm{~g}$ of amoxicillin administered 1-h preoperatively. Even if the single pre-operative dose of $2 \mathrm{~g}$ of amoxicillin is the most used, it achieved only a probability of $0.2 \%$ to be the "Best" one.

Conclusions: Basing on the available RCTs, the use of antibiotic prophylaxis is protective against early implant failures, but there is still insufficient evidence to confidently recommend a specific dosage. The use of post-operative courses does not seem however to be justified by the available literature. 
Prospero registration number: CRD42015029708

\section{Clinical Relevance}

Scientific rationale for study: Whenever antibiotic prophylaxis at implant placement is needed, it is not clear which type of antibiotic, which dose and which regimen are to be preferred.

Principal findings: The protocol with the highest probability of being the "Best" one to prevent IF was the single dose of $3 \mathrm{~g}$ of amoxicillin administered 1-h pre-operatively. Even if the single pre-operative dose of $2 \mathrm{~g}$ of amoxicillin is the most used, it achieved only a probability of $0.2 \%$ to be the "Best" one.

Practical implications: The use of antibiotic prophylaxis is protective against early implant failures, but there is still insufficient evidence to confidently recommend a specific dosage. However, the use of post-operative courses does not seem to be justified.

\section{Introduction}

A Cochrane systematic review of randomized controlled trials (RCTs) highlighted the efficacy of prophylactic antibiotics in reducing early implant failures at dental implant placement (RR 0.33; 95\% CI 0.16-0.67) (Esposito, Grusovin, Worthington, 2013). Nevertheless, also considering the possible adverse reactions (rarely even fatal), the sideeffects and the public health threat due to the antibiotic resistance, the 2015 consensus conference of the EAO stated that antibiotic prophylaxis should not be recommended in "straightforward" implant surgery in systemically healthy patients (World Health Organization, 2014; Lund, Hultin, Tranaeus, Naimi-Akbar, Klingeet, 2015; Klinge, et al., 2015). 
However, whenever antibiotic prophylaxis is needed, these and other systematic reviews were not able to establish which type of antibiotic, which dose and which regimen are to be preferred (Esposito, et al., 2013; Ata-Ali, Quirynen, Teughels, van Steenberghe, 2014; Chrcanovic, Albrektsson, Wennerberg, 2014; Lund, et al., 2015). In fact, even if different antibiotic prophylaxis protocols have been proposed in RCTs versus placebo/no antibiotics, there is a lack of studies comparing them to each other.

Considering that the risk of antimicrobial resistance increases with longer regimens, it would be particularly important to determine if shorter protocols are sufficient to prevent early implant failures, or if longer courses are to be preferred (Harbarth, Samore, Lichtenberg, Carmeli, 2000).

Recently, a new type of meta-analysis has been introduced in dental literature: the network meta-analysis (NMA) (Tu, Woolston, Faggion, 2010; Tu \& Faggion, 2012; Tu, Needleman, Chambrone, Lu, Faggion, 2012; Buti, Glenny, Worthington, Nieri, Baccini, 2011). Compared to conventional meta-analysis ("pairwise meta-analysis"), the NMA (Buti, et al., 2011; John, Michalowicz, Kotsakis, Chu, 2017):

1) allows to compare more than only two interventions simultaneously;

2) allows indirect comparisons among interventions even when 'head-to-head' studies (direct comparisons) have not been conducted.

These two advantages are particularly relevant in the scientific context of antibiotic prophylaxis at implant placement, characterized by numerous protocols proposed (versus placebo/no antibiotic) but few direct comparisons between them. 
However, to the best of our knowledge, no NMAs have been already conducted to assess which is the best antibiotic prophylaxis protocol to prevent early implant failures. So that, this systematic review of RCTs with NMA was designed to answer the following question:

"In patients undergoing dental implant placement, which is the best antibiotic prophylaxis protocol to prevent early failures?”.

Secondary, this study aims to obtain each 'head-to-head' comparison between all the proposed protocols (even between those not directly compared yet) and to verify the efficacy of any of them when compared to placebo/no antibiotic.

\section{Materials and Methods}

2.1 Report and protocol

This systematic review is reported according to the PRISMA for Network Meta-Analyses (PRISMA-NMA) guidelines (Hutton, et al., 2015).

A detailed protocol was designed by one review author (MR) before the start of this study and registered on Prospero (CRD42015029708).

\subsection{Inclusion and exclusion criteria}

The inclusion criteria of this systematic review were organized by the PICOS acronym.

(P) Types of participants. All type of patients undergoing dental implant placement.

(I) Types of interventions. Any type of antibiotics, administered pre-operatively, intraoperatively, post-operatively or combinations of these, at any dose and for any duration. 
(C) Comparison between interventions. All possible comparisons among the included antibiotic types and posologies, including placebo and no antibiotic.

(O) Type of outcome measures. Early implant failures (removal of mobile implants, or removal of stable implants caused by progressive marginal bone loss or infection in the first year after placement) and/or Adverse Events.

(S) Types of studies. Only RCTs of at least 3 months' follow-up and including at least 20 patients for each arm.

No studies have been excluded on the basis of language, date of publication or publication status.

2.3 Search methods for identification of studies

\subsubsection{Electronic searches}

For the search strategy of MEDLINE (via PubMed) we relied on "Cochran Highly Sensitive Search Strategy for Identifying randomized trials in MEDLINE: sensitivity-maximizing version (2008 revision); PubMed format" (Lefebvre, Manheimer, Glanville, 2011). We developed the other electronic searches appropriately revisiting our strategy for MEDLINE (via PubMed).

The following electronic databases were searched:

- MEDLINE via PUBMED (up to 4th July 2017);

- SCOPUS (up to 7th July 2017);

- The Cochrane Central Register of Controlled Trials (CENTRAL) (up to 4th July 2017);

- Web of Science (up to 4th July 2017). 
The complete search strategies for all electronic databases are reported in Appendix (Appendix 1-4). We did not place any restrictions on language or date of publication when searching the electronic databases.

\subsubsection{Handsearching and grey literature}

The following leading implant journals were hand-searched in duplicate by two review authors (CQ, MDA) up to 10/07/2017:

- Journal of Clinical Periodontology;

- Clinical Oral Implants Research;

- Clinical Implant Dentistry and Related Research;

- Journal of Periodontology;

- European Journal of Oral Implantology;

- The International Journal of Oral \& Maxillofacial Implants.

Moreover, two review authors (MR, CQ) checked in duplicate the bibliographies of all the included RCTs and of relevant review articles (Esposito, et al., 2013; Chrcanovic, et al., 2014; Schwartz \& Larson, 2007; Ata-Ali, et al., 2014; Sharaf, Jandali-Rifai, Susarla, Dodson, 2011, Lund, et al., 2015).

Finally, to explore ongoing trials and the grey literature, two review authors (FC, IDT) searched in duplicate in ClinicalTrials (clinicaltrials.gov), OpenSIGLE (opensigle.inist.fr) and in the National Technical Information Service (NTIS - www.ntis.gov/) up to $12^{\text {th }}$ July 2017 (search strategy reported in Appendix 5). 
Each study identified by at least one review author through the various search strategies was involved in the next stage (study selection).

\subsection{Study selection}

The titles and abstracts (when available) of all reports identified through the electronic searches were screened independently by two review authors (IDT, FC). For studies appearing to meet the inclusion criteria, or for which there was insufficient data in the title and abstract to make a clear decision, the full report was obtained.

The full reports obtained from all the electronic sources and the other methods of searching were assessed independently by two review authors (MR, MDA) to establish whether or not the studies met the inclusion criteria. Any disagreement was discussed by the two review authors and a third review author (GP) was consulted when resolution was not possible. The reasons for exclusion of studies after the full texts analysis were recorded.

All studies meeting the inclusion criteria were then included and underwent validity assessment and data extraction.

\subsection{Data extraction}

Data from included studies were extracted by two review authors (MR, FC) independently using predefined data extraction forms. Any disagreement was discussed by the two review authors and a third review author (GP) was consulted when resolution was not possible. If necessary, trial authors were contacted for clarification or missing information. 
For each trial the following data were recorded:

- General information: year of publication, correspondence details, country of origin, setting (e.g. university, private practice).

- Methods: study design, number of centers.

- Participants: number of participants and their characteristics (age, gender, smokers, bone reconstruction procedures), criteria for inclusion and exclusion.

- Interventions and comparisons: number of intervention groups, types and posologies of the interventions, surgical technique, type of implants, pre- and post-operative instructions.

- Outcomes: details of the outcomes collected (types, definitions, time points).

- Results: number of participants allocated to each intervention group, drop-outs, characteristics of the patients in each group (age, gender, smokers, bone reconstruction procedure), results for each outcome considered (number of events and patients for each group).

- Study funding: information about possible study funding.

- Risk of bias (see the next section).

\subsection{Assessment of risk of bias in included studies}

The risk of bias assessment of the included trials was completed independently and in duplicate by two review authors (MR, FC) as part of the data extraction process. Any disagreement was discussed between the same two review authors and a third review author (GP) was consulted in case there was no further agreement.

It was conducted using the recommended approach for assessing risk of bias in studies included in Cochrane reviews (Higgins, Altman, Sterne, 2011) and reported using RevMan (Version 5.3.5, Copenhagen: The Nordic Cochrane Centre, The Cochrane Collaboration, 2014). 
Briefly, in the first part, the risk of bias for the seven specific domains was assessed for each included study. When for some domain there was insufficient information to determine the risk of bias for a trial (unclear risk of bias), we tried to contact the authors to obtain more information; in case of further absence of exhaustive information, we confirmed the category 'unclear risk of bias'.

Due to the different intrinsic nature of the two outcomes considered (Implant Failures = objective; Adverse Events = subjective), the Risk of Performance, Detection and Attrition Biases within each study were analyzed separately in relation to each one of them. Then, we made a summary of assessments of risk of bias within each study and across all studies, separately for the two outcomes, using the "Possible approach for summary assessment of the risk of bias" (Higgins, et al., 2011).

Due to the small number of included trials, no study was excluded on the basis of the risk of bias within a study; instead, the risk of bias within studies and across all studies was considered in the discussion.

2.7 Measure of intervention effect and unit of analysis

Since all variables were dichotomous, the estimate of effect of an intervention was expressed as odd ratio (OR) together with $95 \%$ confidence interval (CI).

The statistical unit was the participant. We used intention-to-treat data whenever possible (Newell, 1992).

\subsection{Data synthesis and analysis}

\subsubsection{Description of the available evidence}

We firstly presented the characteristics of the included studies and reported all the antibiotic prophylaxis protocols proposed and the individual study results. 
The available direct comparisons between different protocols were then illustrated through a network diagram. The geometry of the network was described and analyzed through the probability of interspecific encounter (PIE) index. We excluded from the NMA every trial not connected to the network diagram.

\subsubsection{Assessment of transitivity}

The transitivity assumption was evaluated conceptually scanning for important differences in terms of inclusion criteria, patient and intervention characteristics and methodology. Clinical and methodological heterogeneity was identified and distribution of potential effect modifiers was estimated.

\subsubsection{Assessment of inconsistency}

In order to assess the presence of statistical inconsistency both local and global approaches were considered to be implemented. In case of closed loops of interventions (both direct and indirect evidence for intervention comparisons), consistency was planned to be evaluated statistically through the loop-specific approach, through the ifplot command on Stata (Salanti, Del Giovane, Chaimani, Caldwell, Higgins, 2014). To assess the global inconsistency a design-by-intervention interaction model was planned. However, due to the large number of "no-event", statistical calculation of inconsistency factors was not possible. Because of the large contribution that indirect evidence had on the total estimate, NMAs were conducted following an inconsistency model (Jackson, Barrett, Rice, White, Higgins, 2014). 


\subsubsection{Meta-analyses of direct comparisons}

In presence of at least two studies for a direct comparison (either no antibiotics vs. antibiotics or among different protocols), a meta-analysis was conducted and heterogeneity was estimated.

\subsubsection{Network meta-analysis (NMA)}

We carried out a network meta-analysis to synthesize the available evidence from the entire network of trials by integrating direct and indirect estimates. We assumed that any patient who met the inclusion criteria was, in principle, equally likely to be randomized to any of the eligible interventions. Protocols based on placebo or no antibiotics were merged into a single group. An adjunctive network meta-analysis with larger groupings was also carried out, but it was reported as Supporting Information as the results were inconclusive and not informing (Appendix 7).

We also assessed the probability that each protocol was the most efficacious regimen, the second best and so on, using the distribution of the ranking probabilities and the surface under the cumulative ranking curves (SUCRA) (Salanti, Ades, Ioannidis, 2011). We planned to conduct subgroup and sensitivity analyses to investigate the effect of different important variables and risk of bias. However, we did not perform any of them because of the limited number of included studies. All analyses were conducted in a frequentist framework using network package and network graphs package on Stata 13 (StataCorp, College Station, TX, USA) (White, 2015; Chaimani \& Salanti, 2015). 


\section{Results}

\subsection{Study selection}

The flow diagram of the study selection process is reported in Figure 1.

The search strategies provided a total of 2,248 citations after duplicates removal. Of these, 2,226 studies were discarded after reviewing the titles and abstracts, confirming the broad nature of the search. The full text of the remaining 22 citations was examined in detail, however 10 of them did not meet the inclusion criteria and were then excluded (reasons for exclusion after full texts analyses reported in Table S1).

We have also found other 3 unpublished trials to be probably included in our systematic review (citations reported in Table S2). However, despite our efforts in retrieving them, the authors of those studies were not able to send us the full data, so it was not possible to $\begin{array}{lllll}\text { include them } & \text { our review. }\end{array}$ Eight studies involving 8 trials met the inclusion criteria and were then included (Abu-Ta'a, Quirynen, Teughels, van Steenberghe, 2008; Esposito, et al., 2008; Anitua, et al., 2009; Esposito, et al., 2010; Caiazzo, Casavecchia, Barone, Brugnami, 2011; El-Kholey, 2014; Nolan, Kemmoona, Polyzois, Claffey, 2014; Arduino, Tirone, Schiorlin, Esposito, 2015).

One other study was included after searching the grey literature and contacting the authors (Moslemi, et al., 2015), for a total of 9 included trials, randomly assigning 1,693 patients in need of implant placement to 10 different antibiotic prophylaxis protocols (including placebo/no antibiotics).

\subsection{Characteristics of the included studies}

Table 1 depicts the general characteristics of the included studies. Seven of the included trials compared the use of one or more protocols of antibiotic prophylaxis with no prophylaxis or prophylaxis with a placebo (Abu-Ta'a, et al., 2008; Esposito, et al., 2008; Anitua, et al., 
2009; Esposito, et al., 2010; Caiazzo, et al., 2011; Nolan, et al., 2014; Moslemi, et al., 2015). The remaining two trials compared the use of different protocols, without the use of a no prophylaxis/placebo group (El-Kholey, 2014; Arduino, et al., 2015).

The antibiotic type used in every trial was only amoxicillin (without clavulanic acid): there were no trials looking at alternative antibiotics. Doses and timing of doses varied, although most protocols used a single dose taken just before the implant placement (Figure 2a).

Detailed characteristics of the included studies regarding Participants, Study Procedures and Outcomes are reported, respectively, in Table S3, S4 and S5.

\subsection{Results of the individual studies}

The results of the individual included trials regarding implant loss and adverse events are reported in Table 2.

Only three trials compared different antibiotic prophylaxis protocols directly (Caiazzo, et al., 2011; El Kholey, 2014), but all of them were underpowered to highlight statistically significant differences.

The implant failure rate was $5.6 \%$ in patients not receiving antibiotics and $1.8 \%$ in the receiving ones. However, among patients not receiving antibiotic prophylaxis, the failure rate changed a lot among the included studies. In particular, Moslemi et al. (2015) (9\%) and Nolan et al. (2013) (17.9\%) showed the highest implant failure rates in patients not receiving antibiotic prophylaxis, especially if related with the $0 \%$ failure rate of their control groups. When a meta-analysis of direct comparisons was done, the use of antibiotic prophylaxis was protective in terms of implant loss $(\mathrm{OR}=0.28$; 95\% CI: $0.14-0.55$; heterogeneity chi-squared 4.14, $\mathrm{P}=0.66$ ), and the significance was maintained also excluding the aforementioned studies (data not shown). 
Generally, extremely few adverse events in people using antibiotics were reported (4 out of 947 patients receiving antibiotics) and almost all of them (3) were related to the use of prolonged courses (Arduino, et al., 2015).

3.4 Transitivity (similarity of participants, interventions and trial methodology)

The evaluation of the transitivity assumption is reported in Appendix 6.

\subsection{Risk of bias within studies}

The Risk of Bias within studies is depicted in Figure 3 and it changed a lot after additional information kindly provided by the respective authors.

For both the outcomes considered, two trials had to be considered at low risk of bias (Anitua, et al., 2009; Esposito, et al., 2010) and seven at high risk of bias (all the others).

However, methodological quality of the included studies was generally good. Across all domains, $75.0 \%$ of judgments was 'low risk', 3.6\% was "unclear" and $21.4 \%$ was 'high', with the majority of high bias domains related with Adverse Events assessment.

\subsection{Network meta-analysis (NMA)}

Due to the extremely few events reported, a NMA for Adverse Events was not indicated. So that, the NMA was only performed for Implant Failures. Moreover, Protocols I and J were not connected to the network for IF, so it was not possible to include them in the NMA (Figure 2b).

The network characteristics are reported in Table S6: there were 28 possible pairwise comparisons in the network, but only 10 of them were already directly tested in trials. 
The effect size estimates for all the possible pairwise comparisons between the included protocols are reported in Figure 4. All protocols were more effective in reducing implant failures compared to placebo/no antibiotic (mean OR 0.08 to 0.45 ). Meta-analysis of direct comparison was only possible for the four trials comparing B to A (unpublished data), indicating $\mathrm{B}$ as more effective (pulled $\mathrm{OR}=0.40 ; 95 \% \mathrm{CI}$ : $0.19-0.88$; heterogeneity chisquared 1.40, $\mathrm{P}=0.706$ ). These results were consistent with NMA effect estimates (mean $\mathrm{OR}=0.45 ; 95 \%$ CI: 0.02-10.93).

The probability for each protocol to be the best in reducing implant failures is reported in Table 3. The antibiotic prophylaxis protocol with the highest probability of being the best to prevent implant failures was the Protocol C (single dose of $3 \mathrm{~g}$ of amoxicillin administered 1h pre-operatively) $(\operatorname{PrBest}=32.5 \%, \mathrm{SUCRA}=74.1 \%)$. This protocol was statistically more effective in reducing implant failures if compared to no prophylaxis/placebo $(\mathrm{OR}=0.41,95 \%$ $\mathrm{CI}=0.18-0.91)$.

The single dose of $2 \mathrm{~g}$ of amoxicillin administered 1-h pre-operatively achieved only a probability of $0.2 \%$ to be the best one. Finally, the Protocol A (placebo/no antibiotics) was the least favorable out of the eight protocols tested (PrBest $=0 \%)$.

\section{Discussion}

4.1 Main results

This systematic review with NMA of RCTs indicates the single dose of $3 \mathrm{~g}$ of amoxicillin administered 1 hour pre-operatively as the protocol with the highest probability to be the best to prevent early implant failures. Even if a single dose of $2 \mathrm{~g}$ of amoxicillin administered 1-h pre-operatively is the most commonly used protocol and is the one suggested by the Cochrane Collaboration (Esposito, et al., 2013), it achieved only a probability of $0.2 \%$ to be the best one. 
In the direct meta-analysis, the use of antibiotic prophylaxis was protective in term of implant loss. Moreover, all the examined antibiotic prophylaxis protocols have shown a trend of increased efficacy in reducing implant failures when compared to placebo/no antibiotic. These findings extend to each single protocol, what already evidenced in a general manner in the Cochrane systematic review on the efficacy of antibiotic prophylaxis in preventing early implant failures (Esposito, et al., 2013).

However, these results need to be interpreted with caution due to the large CI for the majority of protocols, attributable to the lack in statistical power and heterogeneity among trials.

Moreover, even if it was not possible to carry out a NMA for adverse events, there was a clear tendency towards the manifestation of adverse events mainly with the use of prolonged courses of antibiotics. In fact, the majority of the reported adverse events (3) were concentrated in the minority of patients subjected to the use of post-operative antibiotics. This increase in adverse events was not balanced by an increased efficacy in reducing implant failures with prolonged courses.

The antibiotic type used in every trial was only amoxicillin without clavulanic acid: there were no trials looking at alternative antibiotics. So that, there is no evidence of efficacy for patients who are not able to take penicillins (e.g. allergic patients). Moreover, there is no evidence on the added benefits of clavulanic acid, even if in many countries amoxicillin is mainly prescribed in combination with it.

\subsection{Interpretation in the context of the available literature}

The findings of the present NMA corroborate the efficacy of all single proposed antibiotic prophylaxis protocols in reducing early implant failures, already evidenced in a general 
manner in other available SRs (Esposito, et al., 2013; Ata-Ali, et al., 2014; Chrcanovic, et al., 2014; Lund, et al., 2015). However, it was beyond the scopes of this SR to draw indications whether or not to use antibiotic prophylaxis in the different clinical situations.

The main aim of this SR was to identify the best protocol among the ones proposed, whenever an antibiotic prophylaxis is needed, and it appeared to be the single pre-operative dose of $3 \mathrm{~g}$ of amoxicillin. In this respect, our results are not directly comparable with RCTs and/or other SRs. In fact, we only found 4 RCTs directly comparing some of the different antibiotic prophylaxis protocols, but no one of them was able to evidence statistically significant differences due to a clear lack in statistical power (Caiazzo, et al., 2011; ElKholey, 2014; Arduino, et al., 2015), while the last one has a 8-weeks follow-up and then it was not included (Tan, et al., 2014). Moreover, to the best of our knowledge, no previous NMAs have been conducted on this topic. So that, our results partially fill the gap in knowledge on the best protocol among the ones proposed, already highlighted by the Cochrane Collaboration (Esposito, et al., 2013). However, our results are partially in disagreement with the conclusions of the SR of the Cochrane Collaboration, which - in lack of evidence - suggested the use of a single dose of $2 \mathrm{~g}$ of prophylactic amoxicillin (Esposito, et al., 2013).

Finally, our findings are in agreement with the generally principle that, without compelling evidence highlighting superiority of one protocol, responsible antibiotic use recommends the highest dose for the shortest duration of time to reduce the risk of antibiotic resistance (McGowan, McGowan, Ivanovski, 2018). 
4.3 Limitations and Strengths of the systematic review and of the included studies

At the "systematic review" level, no important limitations could be observed. However, some limitations need to be discussed at the "available studies" and the "network meta-analysis" levels.

Regarding the "available studies", only few published RTCs (9) were found. Most of the included studies (7 out of 9) were at high risk of bias for both the outcomes. However, it needs to be considered how one study (El-Kholey, 2014) was considered not to be at low risk only because it didn't collect adverse events, while another one (Esposito, et al., 2008) accomplished all the domains but it was not possible to be considered at low risk because there was a clear baseline imbalance, probably due to the reasonably justified drop-outs. Moreover, four studies reported only 'available case' data (Esposito, et al., 2008; Esposito, et al., 2010; Nolan, et al., 2014; Arduino, et al., 2015; Moslemi, et al., 2015), some studies used no antibiotic instead of placebo (Abu-Ta'a, et al., 2008; Caiazzo, et al., 2011) and, as already noted, the antibiotic type used in every trial was only amoxicillin without clavulanic acid.

Post-operative posologies were often not reported in detail (e.g. not clear if the post-operative antibiotic was started the same day of the surgery or the following one).

In addition, adverse events appeared to have been collected not systematically and, even after correspondence with authors, often their assessment methods remained unclear (e.g. definitions, if asked or self-reported, when and how): this could explain the lower reported rates if compared with the medical literature (Tandan, et al., 2017). Moreover, there was generally a poor report of periodontal conditions of participants and differences in the experience of the operators and in pre- and post-operative procedures (e.g., sterility, irrigation, one- or two-phases surgery, PRGF use in one trial, loading protocols), which could potentially influence implant failures. In addition, only one of the trials using post-operative 
antibiotics implemented the use of compliance measures (Arduino, et al., 2015). Finally, all of the trials comparing different protocols were clearly underpowered, not all the studies performed sample size calculations and - even when calculated - the planned sample sizes were often not reached. Considering that to highlight an effect of antibiotics in reducing early failures a meta-analysis of 1,162 participants was needed (no primary trial was able to evidence it) (Esposito, Grusovin, Worthington, 2013), it is likely that many thousands of patients are needed to discern differences among different doses and duration of the same molecule (which are expected to be lower).

Regarding the "network meta-analysis", the confidence intervals were generally large (probably due to the high heterogeneity and to the lack of statistical power). However, this problem represents a common issue with the majority of NMAs (especially those with dichotomous outcome measures).

Moreover, it was not possible to carry out a NMA for outcomes different to IF, in particular for the adverse events. It should be taken in account how, in the context of the protocols found, adverse events could even be considered the primary outcome, considering the little anticipated differences in efficacy between different doses and durations of the same antibiotic type (amoxicillin).

In addition, another limitation is that many " 0 cells" were present in the network metaanalysis, considering that the event "early implant failure" has generally a low incidence.

Finally, a relevant limitation is that the protocol with the highest probability to be the best one (single pre-operative dose of $3 \mathrm{~g}$ of amoxicillin) was only tested in one included RCT. This trial (Nolan, et al., 2014) has in the control group (no antibiotic) an unusual high incidence of implant failures (17.9\%) when compared with the control groups of the other included studies (5.6\% as mean, the second one is $9 \%$ of Moslemi et al. 2015). Moreover, it 
has only few included patients ( 27 treated with the 3 grams protocol), the surgeries were all carried out by postgraduate students and it was considered at high risk of bias, in particular for the numerous exclusions after randomization.

Despite these limitations, this represents the first SR with NMA comparing all of the antibiotic prophylaxis protocols to prevent early implant failures. Only RCTs were included, for a total of 1.693 participants. The systematic analysis of the literature was done in accordance with the guidelines of the Cochrane Collaboration (Higgins \& Green, 2011). The intense search process allowed us also to identify 4 trials in the grey literature, and to include in our SR one of them which was previously ignored (Moslemi, et al., 2015). Moreover, the deep analysis of the included studies will be crucial to guide future research in this field (see later).

In absence of RCTs comparing directly the different protocols and with enough statistical power, this study provides evidence to partially fill this gap in knowledge. In fact, the advantages of NMAs are particularly evident in the scientific context of antibiotic prophylaxis at implant placement, characterized by numerous protocols proposed (versus placebo/no antibiotic) but few direct comparisons between them. The only better alternative to a NMA would probably be to carry out RCTs with many thousands of participants, but they are very difficult to achieve.

\section{Conclusions}

\subsection{Implications for Practice}

The limited evidence available from RCTs, suggests how:

- All proposed protocols have the tendency to reduce early implant failures; 
- The most suggested protocol (single pre-operative dose of $2 \mathrm{~g}$ of amoxicillin) does not seem to be indicated by the available literature;

- The use of post-operative antibiotics does not seem to be justified, as prolonged courses were associated with a tendency to higher adverse events not balanced by an increased efficacy in reducing implant failures;

- The single-dose of $3 \mathrm{~g}$ of amoxicillin 1-h pre-operatively seems to be the best when an antibiotic prophylaxis is required at dental implant placement; however, this protocol was only tested in one single high-risk RCT with an unusual high implant failure rate in the control group, so there is still insufficient evidence to confidently recommend this specific dosage.

\subsection{Implications for Research}

The findings of this SR highlight the need of future research in this field. Priority should be given to:

- RCTs - at least with a non-inferiority design - to compare antibiotics different from amoxicillin with the single dose of $3 \mathrm{~g}$ of amoxicillin $1 \mathrm{~h}$ pre-operatively, in order to gain evidence on alternative molecules for patients not able to take penicillins;

- RCTs to verify the presence of added benefits in using clavulanic acid in amoxicillin formulations;

- RCTs to verify the efficacy of antibiotics - and to compare different protocols - in cases where implant failures are more likely to occur (e.g. immediate placement, concomitant to the use of bone-augmentation procedures, etc.);

- RCTs comparing prolonged antibiotic prophylaxis courses with the single dose of $3 \mathrm{~g}$ of amoxicillin $1 \mathrm{~h}$ pre-operatively. 
When carrying out such studies, attention should be paid in particular to the following issues:

- Correct sample size calculations should be done prior to start these trials and then accomplished;

- Clear reporting of posologies and measures of compliance should be implemented;

- Whenever needed, placebo should be preferred to no-antibiotics, in particular because of the influence of that choice on patient-reported adverse events;

- Concentrate on adverse events, in particular when comparing different amoxicillin-based protocols; they should be collected in a standardized way, if possible through the use of diaries with specific questions, and their reporting should be clearer;

- Conditions able to influence implant failures (e.g. periodontal conditions, smoking status, loading protocols, etc.) should be reported meticulously, possibly considering their impact on the results through multivariate analyses.

\section{Acknowledgments}

We would like to kindly thank Mahmoud Abu-Ta'a, Eduardo Anitua, Paolo Arduino, Javier Ata-Ali, Alfonso Caiazzo, Bruno Chrcanovic, Marco Cune, Khalid El-Kholey, Marco Esposito, Gert Meijer, Neda Moslemi, Ioannis Polyzois and Wah Ching Tan for providing with more information about their trials and/or systematic reviews.

Moreover, we are grateful to Adriano Piattelli and Pierluigi Romandini for their important practical help during the realization of this systematic review.

This article is protected by copyright. All rights reserved. 


\section{Supporting Information}

Additional Supporting Information may be found in the online version of this article:

Appendix 1-5. Search strategies for the electronic databases.

Appendix 6. Transitivity assessment (similarity of participants, interventions and trial methodology).

Appendix 7. Network meta-analysis with larger groupings.

Table S1. Excluded studies after full texts analysis and reasons for exclusion.

Table S2. Unpublished trials found.

Table S3. Characteristics of the included studies: Participants.

Table S4. Characteristics of the included studies: Interventions and Study Procedures.

Table S5. Characteristics of the included studies: Outcomes.

Table S6. Network characteristics. 


\section{References}

Abu-Ta'a, M., Quirynen, M., Teughels, W. \& van Steenberghe, D. (2008) Asepsis during periodontal surgery involving oral implants and the usefulness of peri-operative antibiotics: A prospective, randomized, controlled clinical trial. J Clin Periodontol 35: 58-63.

Anitua, E., Aguirre, J. J., Gorosabel, A., Barrio, P., Errazquin, J. M., Roman, P., Pla, R., Carrete, J., de Petro, J. \& Orive, G. (2009) A multicentre placebo-controlled randomised clinical trial of antibiotic prophylaxis for placement of single dental implants. Eur J Oral Implantol 2: 283-292.

Arduino, P. G., Tirone, F., Schiorlin, E. \& Esposito, M. (2015) Single preoperative dose of prophylactic amoxicillin versus a 2-day postoperative course in dental implant surgery: A two-centre randomised controlled trial. Eur J Oral Implantol 8: 143-149.

Ata-Ali, J., Ata-Ali, F. \& Ata-Ali, F. (2014) Do antibiotics decrease implant failure and postoperative infections? A systematic review and meta-analysis. Int J Oral Maxillofac Surg 43: $68-74$.

Buti, J., Glenny, A. M., Worthington, H. V., Nieri, M. \& Baccini, M. (2011) Network metaanalysis of randomised controlled trials: Direct and indirect treatment comparisons. Eur J Oral Implantol 4: 55-62.

Caiazzo, A., Casavecchia, P., Barone, A. \& Brugnami, F. (2011) A pilot study to determine the effectiveness of different amoxicillin regimens in implant surgery. J Oral Implantol 37: 691-696.

Chaimani, A. , \& Salanti, G. (2015). Visualizing assumptions and results in network metaanalysis: the network graphs package. Stata J., 15, 905-50.

Chrcanovic, B. R., Albrektsson, T. \& Wennerberg, A. (2014) Prophylactic antibiotic regimen and dental implant failure: A meta-analysis. J Oral Rehabil 41: 941-956.

El-Kholey, K. E. (2014) Efficacy of two antibiotic regimens in the reduction of early dental implant failure: A pilot study. Int J Oral Maxillofac Surg 43: 487-490.

Esposito, M., Cannizzaro, G., Bozzoli, P., Checchi, L., Ferri, V., Landriani, S., Leone, M., Todisco, M., Torchio, C., Testori, T., Galli, F. \& Felice, P. (2010) Effectiveness of prophylactic antibiotics at placement of dental implants: A pragmatic multicentre placebocontrolled randomised clinical trial. Eur J Oral Implantol 3: 135-143.

Esposito, M., Cannizzaro, G., Bozzoli, P., Consolo, U., Felice, P., Ferri, V., Landriani, S., Leone, M., Magliano, A., Pellitteri, G., Todisco, M. \& Torchio, C. (2008) Efficacy of prophylactic antibiotics for dental implants: A multicentre placebo-controlled randomised clinical trial. Eur J Oral Implantol 1: 23-31.

Esposito, M., Grusovin, M. G. \& Worthington, H. V. (2013) Interventions for replacing missing teeth: Antibiotics at dental implant placement to prevent complications. Cochrane Database Syst Rev: Cd004152. 
Harbarth, S., Samore, M. H., Lichtenberg, D. \& Carmeli, Y. (2000) Prolonged antibiotic prophylaxis after cardiovascular surgery and its effect on surgical site infections and antimicrobial resistance. Circulation 101: 2916-2921.

Higgins, J.P.T. , \& Green, S. (2011). Cochrane Handbook for Systematic Reviews of Interventions (Version 5.1.0) (updated March 2011). The Cochrane Collaboration. Retrieved from http://www.handbook.cochrane.org.

Higgins, J.P.T. , Altman, D.G. , \& Sterne, J.A.C. (2011). Chapter 8: Assessing risk of bias in included studies. In Cochrane Handbook for Systematic Reviews of Interventions (Version 5.1.0). (updated March 2011). eds. Higgins, J.P.T. , \& Green, S. The Cochrane Collaboration. Retrived from http://www.handbook.cochrane.org.

Hutton, B., Salanti, G., Caldwell, D. M., Chaimani, A., Schmid, C. H., Cameron, C., Ioannidis, J. P., Straus, S., Thorlund, K., Jansen, J. P., Mulrow, C., Catala-Lopez, F., Gotzsche, P. C., Dickersin, K., Boutron, I., Altman, D. G. \& Moher, D. (2015) The prisma extension statement for reporting of systematic reviews incorporating network meta-analyses of health care interventions: Checklist and explanations. Ann Intern Med 162: 777-784.

Jackson, D., Barrett, J. K., Rice, S., White, I. R. \& Higgins, J. P. (2014) A design-bytreatment interaction model for network meta-analysis with random inconsistency effects. Stat Med 33: 3639-3654.

John, M. T., Michalowicz, B. S., Kotsakis, G. A. \& Chu, H. (2017) Network meta-analysis of studies included in the Clinical Practice Guideline on the nonsurgical treatment of chronic periodontitis. J Clin Periodontol 44, 603-611. doi:10.1111/jcpe.12726.

Klinge, B., Flemming, T., Cosyn, J., De Bruyn, H., Eisner, B. M., Hultin, M., Isidor, F., Lang, N. P., Lund, B., Meyle, J., Mombelli, A., Navarro, J. M., Pjetursson, B., Renvert, S. \& Schliephake, H. (2015) The patient undergoing implant therapy. Summary and consensus statements. The 4th eao consensus conference 2015. Clin Oral Implants Res 26 Suppl 11: 6467.

Lefebvre, C. , Manheimer, E. , \& Glanville, J. (2011). Chapter 6: Searching for studies. In Cochrane Handbook for Systematic Reviews of Interventions (Version 5.1.0). (updated March 2011). eds. Higgins, J.P.T. , \& Green, S. The Cochrane Collaboration. Retrieved from http://www.handbook.cochrane.org.

Lund, B., Hultin, M., Tranaeus, S., Naimi-Akbar, A. \& Klinge, B. (2015) Complex systematic review - perioperative antibiotics in conjunction with dental implant placement. Clin Oral Implants Res 26 Suppl 11: 1-14.

McGowan, K., McGowan, T. \& Ivanovski, S. (2018) Optimal dose and duration of amoxicillin-plus-metronidazole as an adjunct to non-surgical periodontal therapy: A systematic review and meta-analysis of randomized, placebo-controlled trials. J Clin Periodontol 45: 56-67.

Moher, D., Liberati, A., Tetzlaff, J. \& Altman, D. G. (2009) Preferred reporting items for systematic reviews and meta-analyses: The prisma statement. Bmj 339: b2535. 
Moslemi, N. , Karami, Z. , Miandoab, A. S. , Masoumi, S. , Shayesteh, Y. S. , Karimi, A. , Ghoncheh, Z. (2015). The efficacy of long-term post-operative antibiotic therapy versus placebo on dental implants. Thrita, 4(3), e30678.

Newell, D. J. (1992) Intention-to-treat analysis: Implications for quantitative and qualitative research. Int J Epidemiol 21: 837-841.

Nolan, R., Kemmoona, M., Polyzois, I. \& Claffey, N. (2014) The influence of prophylactic antibiotic administration on post-operative morbidity in dental implant surgery. A prospective double blind randomized controlled clinical trial. Clin Oral Implants Res 25: 252-259.

Salanti, G., Ades, A. E. \& Ioannidis, J. P. (2011) Graphical methods and numerical summaries for presenting results from multiple-treatment meta-analysis: An overview and tutorial. J Clin Epidemiol 64: 163-171.

Salanti, G., Del Giovane, C., Chaimani, A., Caldwell, D. M. \& Higgins, J. P. (2014) Evaluating the quality of evidence from a network meta-analysis. PLoS One 9: e99682.

Schwartz, A. B. \& Larson, E. L. (2007) Antibiotic prophylaxis and postoperative complications after tooth extraction and implant placement: A review of the literature. J Dent 35: $881-888$

Sharaf, B., Jandali-Rifai, M., Susarla, S. M. \& Dodson, T. B. (2011) Do perioperative antibiotics decrease implant failure? J Oral Maxillofac Surg 69: 2345-2350.

Tan, W. C., Ong, M., Han, J., Mattheos, N., Pjetursson, B. E., Tsai, A. Y., Sanz, I., Wong, M. C. \& Lang, N. P. (2014) Effect of systemic antibiotics on clinical and patient-reported outcomes of implant therapy - a multicenter randomized controlled clinical trial. Clin Oral Implants Res 25: 185-193.

Tandan, M., Vellinga, A., Bruyndonckx, R., Little, P., Verheij, T., Butler, C. C., Goossens, H. \& Coenen, S. (2017) Adverse effects of amoxicillin for acute lower respiratory tract infection in primary care: Secondary and subgroup analysis of a randomised clinical trial. Antibiotics (Basel) 6.

Tu, Y. K. \& Faggion, C. M., Jr. (2012) A primer on network meta-analysis for dental research. ISRN Dent 2012: 276520.

Tu, Y. K., Needleman, I., Chambrone, L., Lu, H. K. \& Faggion, C. M., Jr. (2012) A bayesian network meta-analysis on comparisons of enamel matrix derivatives, guided tissue regeneration and their combination therapies. J Clin Periodontol 39: 303-314.

Tu, Y. K., Woolston, A. \& Faggion, C. M., Jr. (2010) Do bone grafts or barrier membranes provide additional treatment effects for infrabony lesions treated with enamel matrix derivatives? A network meta-analysis of randomized-controlled trials. J Clin Periodontol 37: 59-79.

White, IR. (2015). Network meta-analysis. Stata J.,15, 951-85. 
World Health Organization. WHO Library Cataloguing-in-Publication Data. (2014). Antimicrobial resistance: global report on surveillance. [accessed on 14 July 2017]. Retrieved from http://apps.who.int/iris/bitstream/10665/112642/1/9789241564748_eng.pdf

This article is protected by copyright. All rights reserved. 


\section{Tables}

Table 1. General overview of the included studies.

\begin{tabular}{|c|c|c|c|c|c|c|c|c|c|c|c|c|}
\hline \multirow[b]{2}{*}{ Reference } & \multirow[b]{2}{*}{ Country } & \multirow[b]{2}{*}{ Settings } & \multirow[b]{2}{*}{ Design } & \multirow[b]{2}{*}{ N. Centres } & \multirow{2}{*}{$\begin{array}{c}\text { Follow-up } \\
\text { (Implant } \\
\text { Failures) * }\end{array}$} & \multirow{2}{*}{$\begin{array}{l}\text { External Funding } \\
\text { (Type) }\end{array}$} & \multicolumn{2}{|c|}{ Interventions } & \multicolumn{2}{|c|}{ Partecipants } & \multicolumn{2}{|c|}{ Collected Outcomes } \\
\hline & & & & & & & Test & Control & Randomized & Analyzed & $\begin{array}{l}\text { Implant } \\
\text { Failures }\end{array}$ & $\begin{array}{c}\text { Adverse } \\
\text { Events }\end{array}$ \\
\hline $\begin{array}{l}\text { Abu-Ta'a et al. } \\
(2008)\end{array}$ & Belgium & University & Parallel & Single centre & 5 months & None declared & $\begin{array}{l}\text { Amoxicillin } 1 \mathrm{~g} \text { orally, } 1 \mathrm{~h} \\
\text { pre-operatively }+500 \mathrm{mg} \\
\text { four times per day, for } 2 \\
\text { days post-operatively }\end{array}$ & No antibiotics & 80 & 80 & Yes & Yes \\
\hline $\begin{array}{l}\text { Anitua et al. } \\
\text { (2009) }\end{array}$ & Spain & $\begin{array}{l}\text { Private } \\
\text { practice }\end{array}$ & Parallel & $\begin{array}{l}\text { Multicentric (8 } \\
\text { centers) }\end{array}$ & 3 months & $\begin{array}{l}\text { Yes (Implant } \\
\text { Company: BTI) }\end{array}$ & $\begin{array}{l}\text { Amoxicillin } 2 \mathrm{~g} \text { orally, } 1 \mathrm{~h} \\
\text { pre-operatively }\end{array}$ & $\begin{array}{l}\text { Placebo orally, } 1 \mathrm{~h} \\
\text { pre-operatively }\end{array}$ & 105 & 105 & Yes & Yes \\
\hline $\begin{array}{l}\text { Arduino et al. } \\
(2015)\end{array}$ & Italy & $\begin{array}{l}\text { Private } \\
\text { practice }\end{array}$ & Parallel & $\begin{array}{l}\text { Multicentric } \\
(2 \text { centers })\end{array}$ & 10 months & NR & $\begin{array}{l}\text { Amoxicillin } 2 \mathrm{~g} \text { orally, } 1 \mathrm{~h} \\
\text { pre-operatively }+1 \mathrm{~g} \text { in } \\
\text { the evening of the day of } \\
\text { surgery }+1 \mathrm{~g} \text { twice a day, } \\
\text { for } 2 \text { days post- } \\
\text { operatively }\end{array}$ & $\begin{array}{l}\text { Amoxicillin } 2 \mathrm{~g} \\
\text { orally, } 1 \mathrm{~h} \text { pre- } \\
\text { operatively }\end{array}$ & 360 & 343 & Yes & Yes \\
\hline $\begin{array}{l}\text { Caiazzo et al. } \\
\text { (2011) }\end{array}$ & Italy & $\begin{array}{l}\text { Private } \\
\text { practice }\end{array}$ & Parallel & $\begin{array}{l}\text { Multicentric } \\
(2 \text { centers })\end{array}$ & 3 months & NR & $\begin{array}{l}\text { Test } 1 \text { : Amoxicillin } 2 \mathrm{~g} \\
\text { orally, } 1 \mathrm{~h} \text { pre-operatively } \\
\text { Test } 2 \text { : Amoxicillin } 2 \mathrm{~g} \\
\text { orally, } 1 \mathrm{~h} \text { pre-operatively } \\
+1 \mathrm{~g} \text { twice a day, for } 7 \\
\text { days post-operatively } \\
\text { Test } 3 \text { : Amoxicillin } 1 \mathrm{~g} \\
\text { orally twice a day, for } 7 \\
\text { days post-operatively }\end{array}$ & No antibiotics & 100 & 100 & Yes & Yes \\
\hline
\end{tabular}

This article is protected by copyright. All rights reserved. 


\begin{tabular}{|c|c|c|c|c|c|c|c|c|c|c|c|c|}
\hline $\begin{array}{l}\text { El-Kholey } \\
(2014)\end{array}$ & $\begin{array}{l}\text { Saudi } \\
\text { Arabia }\end{array}$ & University & Parallel & Single centre & 3 months & None declared & $\begin{array}{l}\text { Amoxicillin } 1 \mathrm{~g} \text { per os } 1 \mathrm{~h} \\
\text { pre-operatively }+500 \mathrm{mg} \\
\text { three times per day post- } \\
\text { operatively started } 8 \mathrm{~h} \\
\text { after the pre-operative } \\
\text { dose }\end{array}$ & $\begin{array}{c}\text { Amoxicillin } 1 \mathrm{~g} \\
\text { orally, } 1 \mathrm{~h} \text { pre- } \\
\text { operatively }\end{array}$ & 80 & 80 & Yes & No \\
\hline $\begin{array}{l}\text { Esposito et al. } \\
(2008)\end{array}$ & Italy & $\begin{array}{l}\text { Private } \\
\text { practice }\end{array}$ & Parallel & $\begin{array}{l}\text { Multicentric } \\
\text { (11 centers) }\end{array}$ & 4 months & $\begin{array}{c}\text { No (only free antibiotic } \\
\text { and placebo tablets } \\
\text { donated by Merk } \\
\text { Generics Italia) }\end{array}$ & $\begin{array}{l}\text { Amoxicillin } 2 \mathrm{~g} \text { orally, } 1 \mathrm{~h} \\
\text { pre-operatively }\end{array}$ & $\begin{array}{l}\text { Placebo orally, } 1 \mathrm{~h} \\
\text { pre-operatively }\end{array}$ & 330 & 316 & Yes & Yes \\
\hline $\begin{array}{l}\text { Esposito et al. } \\
(2010)\end{array}$ & Italy & $\begin{array}{l}\text { Private } \\
\text { practice }\end{array}$ & Parallel & $\begin{array}{l}\text { Multicentric } \\
\text { (10 centers) }\end{array}$ & 4 months & $\begin{array}{c}\text { No (only free antibiotic } \\
\text { and placebo tablets } \\
\text { donated by Merk } \\
\text { Generics Italia) }\end{array}$ & $\begin{array}{l}\text { Amoxicillin } 2 \mathrm{~g} \text { orally, } 1 \mathrm{~h} \\
\text { pre-operatively }\end{array}$ & $\begin{array}{l}\text { Placebo orally, } 1 \mathrm{~h} \\
\text { pre-operatively }\end{array}$ & 509 & 506 & Yes & Yes \\
\hline $\begin{array}{l}\text { Moslemi et al. } \\
(2015)\end{array}$ & Iran & University & Parallel & Single centre & 6 months & None declared & $\begin{array}{l}\text { Amoxicillin } 500 \text { mg orally } \\
\text { started just after the } \\
\text { surgery and continued } \\
\text { every } 8 \mathrm{~h} \text {, for } 7 \text { days post- } \\
\text { operatively (up to finish } \\
21 \text { capsules) }\end{array}$ & $\begin{array}{l}\text { Placebo orally } \\
\text { started just after } \\
\text { the surgery and } \\
\text { continued every } 8 \mathrm{~h} \text {, } \\
\text { for } 7 \text { days post- } \\
\text { operatively (up to } \\
\text { finish } 21 \text { capsules) }\end{array}$ & 50 & 46 & Yes & No \\
\hline $\begin{array}{l}\text { Nolan et al. } \\
(2014)\end{array}$ & Ireland & University & Parallel & Single centre & 4 months & NR & $\begin{array}{l}\text { Amoxicillin } 3 \mathrm{~g} \text { orally, } 1 \mathrm{~h} \\
\text { pre-operatively }\end{array}$ & $\begin{array}{l}\text { Placebo orally, } 1 \mathrm{~h} \\
\text { pre-operatively }\end{array}$ & 83 & 55 & Yes & Yes \\
\hline
\end{tabular}

\section{Footnote:}

\section{NR, Not reported.}

* Last reported follow-up for implant failures, measured from implant placement; for details refer to Table S5.

This article is protected by copyright. All rights reserved. 
Table 2. Results of the individual included studies; a, Implant Failures; b, Adverse Events.

\begin{tabular}{|c|c|c|c|c|c|c|c|c|c|c|c|c|c|c|c|c|c|c|c|c|c|c|c|}
\hline \multirow[b]{3}{*}{$\#$} & \multirow[b]{3}{*}{$\begin{array}{c}\text { Refer } \\
\text { ence }\end{array}$} & \multirow{2}{*}{\multicolumn{2}{|c|}{$\begin{array}{c}1 \\
\text { Protocol } \\
\text { A(1) }\end{array}$}} & \multirow{2}{*}{\multicolumn{2}{|c|}{$\begin{array}{c}2 \\
\text { Protocol } \\
\mathbf{A}(2) \\
\end{array}$}} & \multicolumn{2}{|c|}{3} & \multicolumn{2}{|c|}{4} & \multicolumn{2}{|c|}{5} & \multicolumn{2}{|c|}{6} & \multicolumn{2}{|c|}{7} & \multicolumn{2}{|c|}{8} & \multicolumn{2}{|c|}{9} & \multicolumn{2}{|c|}{10} & \multicolumn{2}{|c|}{11} \\
\hline & & & & & & Pro & col B & Pro & $\operatorname{col} \mathrm{C}$ & Pro & col D & Pro & $\operatorname{col} \mathbf{E}$ & Pro & col F & Prot & $\operatorname{col} \mathbf{G}$ & Pro & $\operatorname{col} \mathbf{H}$ & Pro & col I & Pro & ocol J \\
\hline & & $\begin{array}{c}\text { Eve } \\
\text { nts }\end{array}$ & $\begin{array}{c}\text { Patie } \\
\text { nts }\end{array}$ & $\begin{array}{c}\text { Eve } \\
\text { nts }\end{array}$ & $\begin{array}{c}\text { Patie } \\
\text { nts }\end{array}$ & $\begin{array}{c}\text { Eve } \\
\text { nts }\end{array}$ & $\begin{array}{c}\text { Patie } \\
\text { nts }\end{array}$ & $\begin{array}{c}\text { Eve } \\
\text { nts }\end{array}$ & $\begin{array}{c}\text { Patie } \\
\text { nts }\end{array}$ & $\begin{array}{c}\text { Eve } \\
\text { nts }\end{array}$ & $\begin{array}{c}\text { Patie } \\
\text { nts }\end{array}$ & $\begin{array}{c}\text { Eve } \\
\text { nts }\end{array}$ & $\begin{array}{c}\text { Patie } \\
\text { nts }\end{array}$ & $\begin{array}{c}\text { Eve } \\
\text { nts }\end{array}$ & $\begin{array}{c}\text { Patie } \\
\text { nts }\end{array}$ & $\begin{array}{c}\text { Eve } \\
\text { nts }\end{array}$ & $\begin{array}{c}\text { Patie } \\
\text { nts }\end{array}$ & $\begin{array}{c}\text { Eve } \\
\text { nts }\end{array}$ & $\begin{array}{c}\text { Patie } \\
\text { nts }\end{array}$ & $\begin{array}{c}\text { Eve } \\
\text { nts }\end{array}$ & $\begin{array}{c}\text { Patie } \\
\text { nts }\end{array}$ & $\begin{array}{c}\text { Eve } \\
\text { nts }\end{array}$ & $\begin{array}{c}\text { Patie } \\
\text { nts }\end{array}$ \\
\hline 1 & $\begin{array}{l}\text { Abu- } \\
\text { Ta'a et } \\
\text { al. } \\
(2008)\end{array}$ & 3 & 40 & & & & & & & & & & & 0 & 40 & & & & & & & & \\
\hline 2 & $\begin{array}{l}\text { Anitua } \\
\text { et al. } \\
(2009)\end{array}$ & & & 2 & 53 & 2 & 52 & & & & & & & & & & & & & & & & \\
\hline 3 & $\begin{array}{l}\text { Ardui } \\
\text { no et } \\
\text { al. } \\
(2015) \\
*\end{array}$ & & & & & $5^{*}$ & $166^{*}$ & & & & & & & & & $5^{*}$ & $177 *$ & & & & & & \\
\hline 4 & $\begin{array}{l}\text { Caiazz } \\
\text { o et al. } \\
(2011)\end{array}$ & 2 & 25 & & & 0 & 25 & & & 0 & 25 & 0 & 25 & & & & & & & & & & \\
\hline 5 & $\begin{array}{l}\text { El- } \\
\text { Khole } \\
\mathrm{y} \\
(2014)\end{array}$ & & & & & & & & & & & & & & & & & & & 0 & 40 & 0 & 40 \\
\hline 6 & $\begin{array}{l}\text { Esposi } \\
\text { to et } \\
\text { al. } \\
(2008) \\
*\end{array}$ & & & $8 *$ & $158 *$ & $2 *$ & $158 *$ & & & & & & & & & & & & & & & & \\
\hline 7 & $\begin{array}{l}\text { Esposi } \\
\text { to et } \\
\text { al. } \\
(2010) \\
*\end{array}$ & & & $12 *$ & $254 *$ & $5^{*}$ & $252 *$ & & & & & & & & & & & & & & & & \\
\hline
\end{tabular}

This article is protected by copyright. All rights reserved. 


\begin{tabular}{|c|c|c|c|c|c|c|c|c|c|c|c|c|c|c|c|c|c|c|c|c|c|c|c|}
\hline 8 & $\begin{array}{l}\text { Mosle } \\
\text { mi et } \\
\text { al. } \\
(2015)\end{array}$ & & & $2^{*}$ & $22^{*}$ & & & & & & & & & & & & & $0^{*}$ & $24 *$ & & & & \\
\hline 9 & $\begin{array}{l}\text { Nolan } \\
\text { et al. } \\
(2014) \\
*\end{array}$ & & & $5^{*}$ & $28 *$ & & & $0^{*}$ & $27 *$ & & & & & & & & & & & & & & \\
\hline \multicolumn{24}{|c|}{$a$} \\
\hline & & \multicolumn{2}{|c|}{1} & \multicolumn{2}{|c|}{2} & \multicolumn{2}{|c|}{3} & \multicolumn{2}{|c|}{4} & \multicolumn{2}{|c|}{5} & \multicolumn{2}{|c|}{6} & \multicolumn{2}{|c|}{7} & \multicolumn{2}{|c|}{8} & \multicolumn{2}{|c|}{9} & \multicolumn{2}{|c|}{10} & \multicolumn{2}{|c|}{11} \\
\hline & & \multicolumn{2}{|c|}{$\begin{array}{c}\text { Protocol } \\
\mathbf{A}(\mathbf{1})\end{array}$} & \multicolumn{2}{|c|}{$\begin{array}{c}\text { Protocol } \\
\text { A(2) }\end{array}$} & \multicolumn{2}{|c|}{ Protocol B } & \multicolumn{2}{|c|}{ Protocol C } & \multicolumn{2}{|c|}{ Protocol D } & \multicolumn{2}{|c|}{ Protocol E } & \multicolumn{2}{|c|}{ Protocol F } & \multicolumn{2}{|c|}{ Protocol G } & \multicolumn{2}{|c|}{ Protocol H } & \multicolumn{2}{|c|}{ Protocol I } & \multicolumn{2}{|c|}{ Protocol J } \\
\hline \# & $\begin{array}{c}\text { Refere } \\
\text { nce }\end{array}$ & $\begin{array}{l}\text { Eve } \\
\text { nts }\end{array}$ & $\begin{array}{l}\text { Patie } \\
\text { nts }\end{array}$ & $\begin{array}{l}\text { Eve } \\
\text { nts }\end{array}$ & $\begin{array}{c}\text { Patie } \\
\text { nts }\end{array}$ & $\begin{array}{l}\text { Eve } \\
\text { nts }\end{array}$ & $\begin{array}{l}\text { Patie } \\
\text { nts }\end{array}$ & $\begin{array}{l}\text { Eve } \\
\text { nts }\end{array}$ & $\begin{array}{c}\text { Patie } \\
\text { nts }\end{array}$ & $\begin{array}{l}\text { Eve } \\
\text { nts }\end{array}$ & $\begin{array}{c}\text { Patie } \\
\text { nts }\end{array}$ & $\begin{array}{l}\text { Eve } \\
\text { nts }\end{array}$ & $\begin{array}{c}\text { Patie } \\
\text { nts }\end{array}$ & $\begin{array}{l}\text { Eve } \\
\text { nts }\end{array}$ & $\begin{array}{c}\text { Patie } \\
\text { nts }\end{array}$ & $\begin{array}{l}\text { Eve } \\
\text { nts }\end{array}$ & $\begin{array}{c}\text { Patie } \\
\text { nts }\end{array}$ & $\begin{array}{l}\text { Eve } \\
\text { nts }\end{array}$ & $\begin{array}{c}\text { Patie } \\
\text { nts }\end{array}$ & $\begin{array}{l}\text { Eve } \\
\text { nts }\end{array}$ & $\begin{array}{c}\text { Patie } \\
\text { nts }\end{array}$ & $\begin{array}{l}\text { Eve } \\
\text { nts }\end{array}$ & $\begin{array}{c}\text { Patie } \\
\text { nts }\end{array}$ \\
\hline 1 & $\begin{array}{l}\text { Abu- } \\
\text { Ta'a } \\
\text { et al. } \\
(2008)\end{array}$ & 0 & 40 & & & & & & & & & & & 0 & 40 & & & & & & & & \\
\hline 2 & $\begin{array}{l}\text { Anitua } \\
\text { et al. } \\
\text { (2009) }\end{array}$ & & & 0 & 53 & 0 & 52 & & & & & & & & & & & & & & & & \\
\hline 3 & $\begin{array}{l}\text { Ardui } \\
\text { no et } \\
\text { al. } \\
(2015) \\
*\end{array}$ & & & & & $0 *$ & $166^{*}$ & & & & & & & & & $3^{*}$ & $177 *$ & & & & & & \\
\hline 4 & $\begin{array}{l}\text { Caiazz } \\
\text { o et al. } \\
\text { (2011) }\end{array}$ & 0 & 25 & & & 0 & 25 & & & 0 & 25 & 0 & 25 & & & & & & & & & & \\
\hline 5 & $\begin{array}{l}\text { El- } \\
\text { Khole } \\
y \\
(2014) \\
\end{array}$ & & & & & & & & & & & & & & & & & & & NC & $\mathrm{NC}$ & NC & NC \\
\hline 6 & $\begin{array}{l}\text { Esposi } \\
\text { to et }\end{array}$ & & & $1 *$ & $158 *$ & $1^{*}$ & $158 *$ & & & & & & & & & & & & & & & & \\
\hline
\end{tabular}

This article is protected by copyright. All rights reserved. 
*'Available case'/‘Per protocol’ data; NC: Not Collected.

Protocol A1: No antibiotics; Protocol A2: Placebo; Protocol B: Amoxicillin 2 g orally, 1 h pre-operatively; Protocol C: Amoxicillin 3 g orally, 1 h pre-operatively; Protocol D: Amoxicillin $2 \mathrm{~g}$ orally, $1 \mathrm{~h}$ pre-operatively $+1 \mathrm{~g}$ twice a day, for 7 days post-operatively; Protocol E: Amoxicillin $1 \mathrm{~g}$ orally twice a day, for 7 days post-operatively; Protocol F: Amoxicillin $1 \mathrm{~g}$ orally, $1 \mathrm{~h}$ pre-operatively +500 mg four times per day, for 2 days post-operatively; Protocol $G$ : Amoxicillin $2 \mathrm{~g}$ orally, $1 \mathrm{~h}$ pre-operatively $+1 \mathrm{~g}$ in the evening of the day of surgery $+1 \mathrm{~g}$ twice a day, for 2 days post-operatively; Protocol $\mathrm{H}$ : Amoxicillin $500 \mathrm{mg}$ orally started just after the surgery and continued every 8 h, for 7 days post-operatively (up to finish 21 capsules); Protocol I: Amoxicillin 1 g orally, 1 h pre-operatively; Protocol J: Amoxicillin 1 g per os $1 \mathrm{~h}$ pre-operatively +500 mg three times oer day post-operatively started $8 \mathrm{~h}$ after the pre-operative dose.

This article is protected by copyright. All rights reserved. 
Table 3. Best, SUCRA and Ranking in relation to Implant Failures as outcome.

\begin{tabular}{cccc}
\hline $\begin{array}{c}\text { Protoc } \\
\text { ol }\end{array}$ & Best (\%) & SUCRA & $\begin{array}{c}\text { Mean } \\
\text { Rank }\end{array}$ \\
\hline A & 0.0 & 9.6 & 7.3 \\
\hline B & 0.2 & 39.2 & 5.3 \\
\hline C & 32.5 & 74.1 & 2.8 \\
\hline D & 14.6 & 56.8 & 4.0 \\
\hline E & 14.2 & 56.5 & 4.0 \\
\hline F & 20.4 & 63.4 & 3.6 \\
\hline G & 1.1 & 41.2 & 5.1 \\
\hline H & 17.0 & 59.0 & 3.9 \\
\hline
\end{tabular}

Footnote:

"Best $(\%)$ " is the probability for each of eight protocols to be the best in terms of reducing implant failures. "SUCRA" is the "Surface Under the Cumulative Ranking Curve". Larger areas under the curve indicate better protocols in terms of reducing implant failures.

"MeanRank" is the mean of the posterior distribution under the NM model: as lower the values of the ranking as higher the position of the protocol in the grading of efficacy (less Implant Failures). 


\section{Figure legends.}

Figure 1. PRISMA 2009 Flow Diagram for study selection.

From: Moher et al. (2009). For more information, please visit www.prisma-statement.org.

- Results of all electronic databases summed; * Specialized Journals, Reference list of included articles and relevant reviews, ClinicalTrials, OpenSIGLE, NTIS; ${ }^{\dagger}$ Reasons for exclusion reported in Table S1; †† Full data not retrieved from the authors (see Table S2).

Figure 2. $a$. List of antibiotic prophylaxis protocols found. $b$. Network diagram: Network of the eight protocols in relation to early implant failures as outcome.

Each node represents an antibiotic prophylaxis protocol and its size is proportional to the number of patients receiving each protocol, considering all the included studies.

The lines refer to direct comparisons (the width of the lines is proportional to the number of RCTs included for each comparison). Protocols I and J were not connected to the network. The calculated PIE was 0.8 , reflecting an acceptable diversity and no particular asymmetry. The network was of a polygon shape, including four triangular closed loops, with the no antibiotic/placebo being the major comparator.

Figure 3. Risk of bias summary: review authors' judgments about each risk of bias item. $a$ Presented for each included study; $b$ Presented as percentages across all included studies. A green circle indicates a low risk of bias for the study regarding the specific domain; a red circle indicates a high risk of bias; a yellow circle indicates that the risk is unclear.

The 3 domains related to Adverse Events were left empty for El-Kholey (2014) and Moslemi et al. (2015) as they did not collect Adverse Events. 
* Blinding of participants and personnel was considered to be able to impact implant failures only when it was not implemented up to the end of the implant placement surgery;

**The lack of blinding for outcome assessment in some studies was considered not to be able to impact the evaluation of implant failures, as it is an objective outcome;

† For RoB assessment, Adverse Events were considered as self-reported by patients in all studies, so that the patients themselves were the outcome assessors for this outcome (detailed information about adverse events assessment methods were not available for all of the included studies);

t† Selective reporting was only evaluated in relation to implant failures and adverse events;

^ High risk for "Other Bias" explained: Abu-Ta'a et al. (2009) in the case they used blocked randomization (not reported), there was the risk to foresee allocation due to the lack of blinding personnel; Caiazzo et al. (2011) there was baseline imbalance for age and gender; Esposito et al. (2008) there was baseline imbalance for gender and smoking; Moslemi et al. (2015) used inappropriate administration of co-interventions (unscheduled immediate orthodontic loading at 1 implant which - after this - failed);

- Abu Ta'a et al. (2008) reported how "Both the surgical team and the patients were blinded to the groups": however, one of the groups was not to use any antibiotics, so 
patients were considered not to be able to be blinded (the authors kindly confirmed this).

Figure 4. Pair-wise results of the network meta-analysis for early implant failures as outcome.

Interval Plot of pair wise comparisons of the network on a logarithmic scale. The black solid lines represent the confidence intervals for summary odds ratios for each comparison. The blue line is the line of no effect.

"OR" is the odds ratio. A value of the "OR" $>1$ is to be interpreted as a difference in efficacy in favor of the second protocol when compared to the first.

Protocol A1: No antibiotics; Protocol A2: Placebo; Protocol B: Amoxicillin 2 g orally, $1 \mathrm{~h}$ pre-operatively; Protocol C: Amoxicillin $3 \mathrm{~g}$ orally, $1 \mathrm{~h}$ pre-operatively; Protocol D: Amoxicillin $2 \mathrm{~g}$ orally, $1 \mathrm{~h}$ pre-operatively $+1 \mathrm{~g}$ twice a day, for 7 days post-operatively; Protocol E: Amoxicillin $1 \mathrm{~g}$ orally twice a day, for 7 days post-operatively; Protocol F: Amoxicillin $1 \mathrm{~g}$ orally, $1 \mathrm{~h}$ pre-operatively $+500 \mathrm{mg}$ four times per day, for 2 days postoperatively; Protocol G: Amoxicillin $2 \mathrm{~g}$ orally, $1 \mathrm{~h}$ pre-operatively $+1 \mathrm{~g}$ in the evening of the day of surgery $+1 \mathrm{~g}$ twice a day, for 2 days post-operatively; Protocol $\mathrm{H}$ : Amoxicillin $500 \mathrm{mg}$ orally started just after the surgery and continued every $8 \mathrm{~h}$, for 7 days post-operatively (up to finish 21 capsules). 


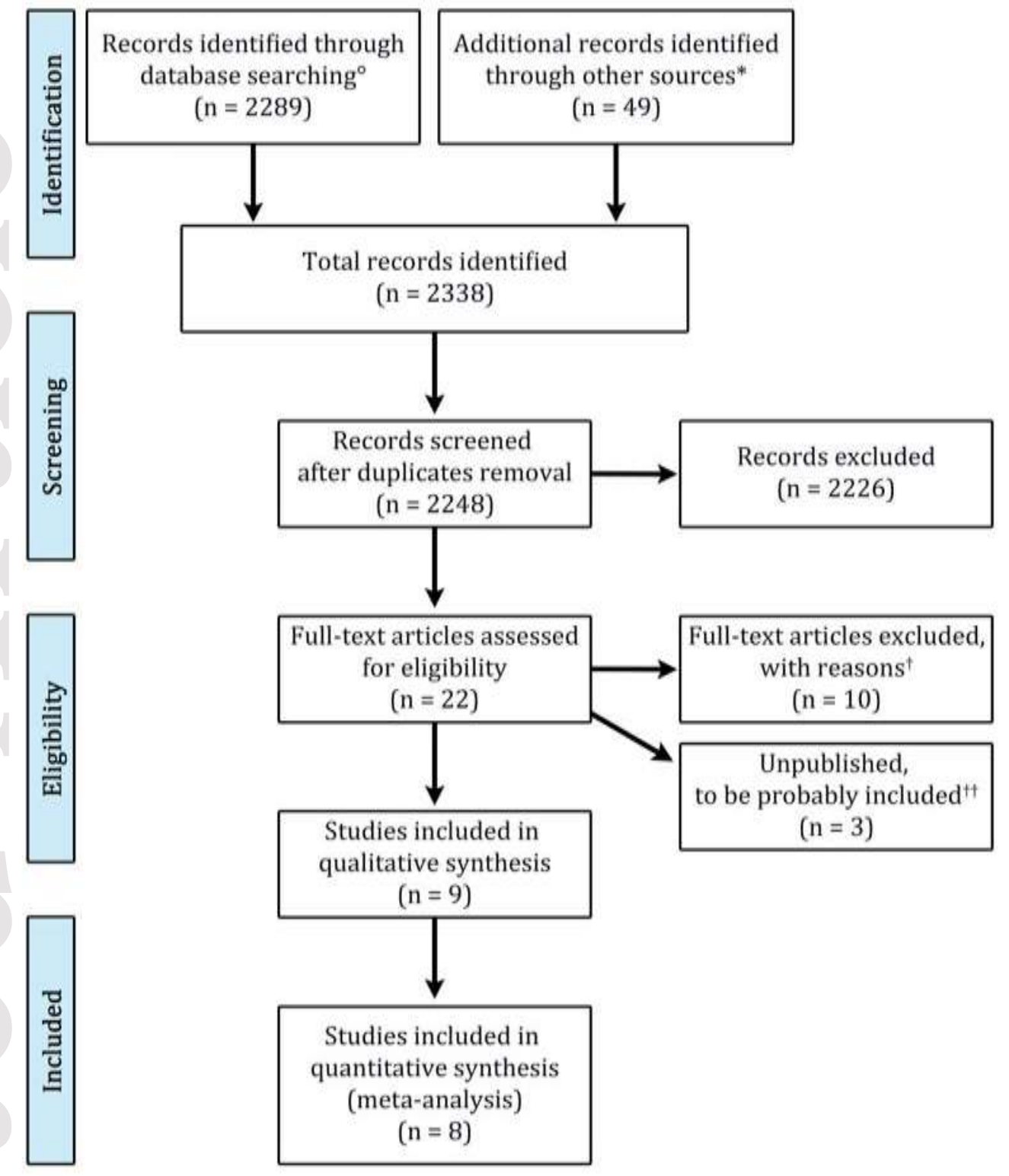

This article is protected by copyright. All rights reserved. 
Protocol A1 No antibiotics;

Protocol A2 Placebo;

Protocol B Amoxicillin $2 \mathrm{~g}$ per os, $1 \mathrm{~h}$ pre-operatively:

Protocol C Amoxicillin $3 \mathrm{~g}$ per os, $1 \mathrm{~h}$ pre-operatively:

Protocol D Amoxicillin $2 \mathrm{~g}$ per os, $1 \mathrm{~h}$ pre-operatively $+1 \mathrm{~g}$ twice a day, for 7 days post-operatively;

Protocal Amoxicillin $1 \mathrm{~g}$ per os twice a day, for 7 days post-operatively;

Protocol $\mathrm{F}$ Amoxicillin $1 \mathrm{~g}$ per os, $1 \mathrm{~h}$ pre-operatively

$+500 \mathrm{mg}$ four times per day. for 2 days post-operatively;

Protocol G Amoxicillin $2 \mathrm{~g}$ per $05,1 \mathrm{~h}$ pre-operatively $+1 \mathrm{~g}$ in the evening of the day of surgery $+1 \mathrm{~g}$ twice a day, for 2 days post-operatively:

Protocol H Amoxicillin $500 \mathrm{mg}$ per os started just after the surgery and continued every $8 \mathrm{~h}$, for 7 days post-operatively (up to finish 21 capsules):

Protocol 1 Amoxicillin $1 \mathrm{~g}$ per $05,1 \mathrm{~h}$ pre-operatively:

Protocol I Amoxicillin $1 \mathrm{~g}$ per os $1 \mathrm{~h}$ pre-operatively $+500 \mathrm{mg}$ three times per day post-operatively started $8 \mathrm{~h}$ after the pre-operative dose.

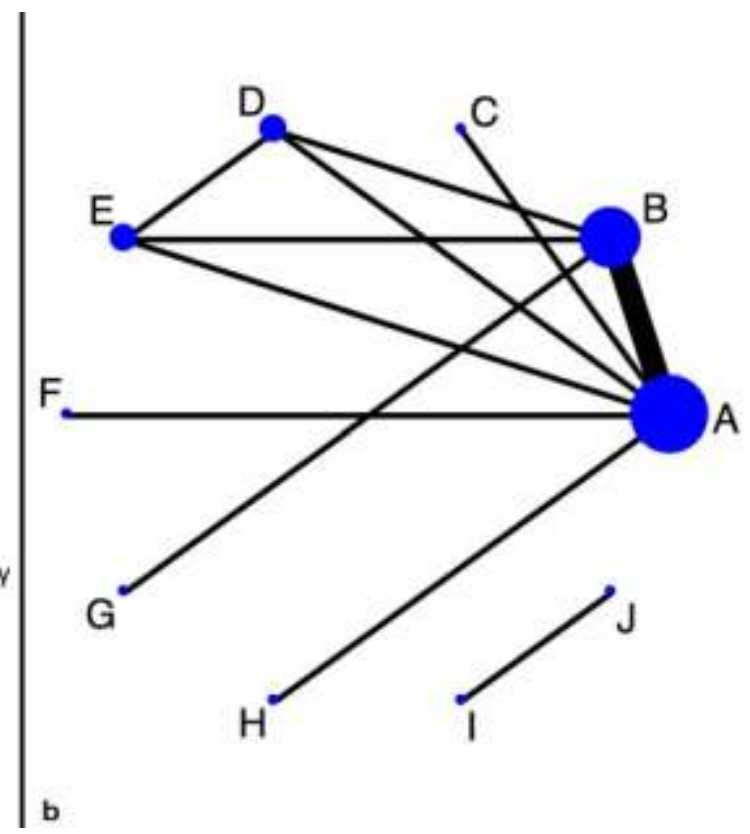

b

a

This article is protected by copyright. All rights reserved. 


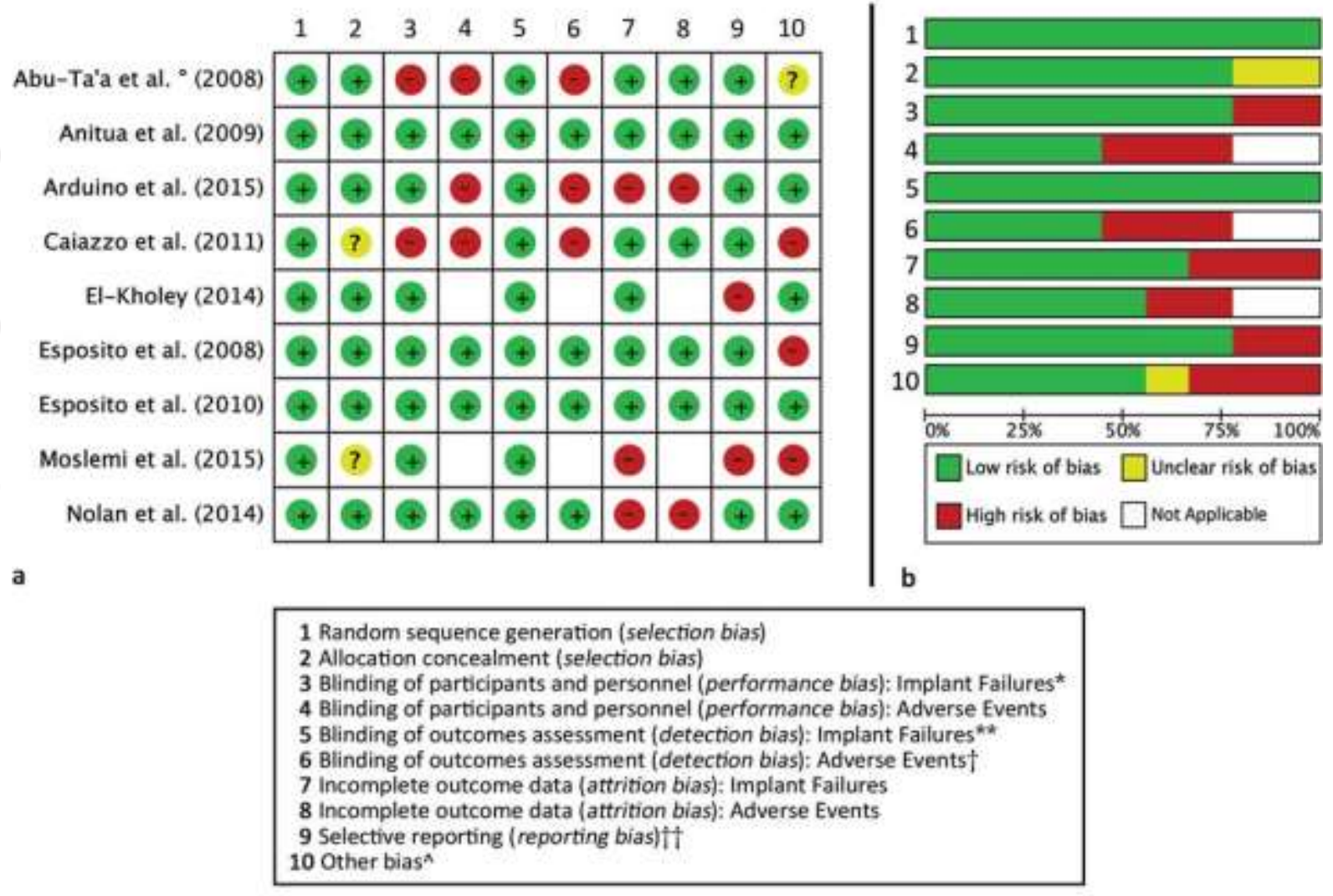

This article is protected by copyright. All rights reserved. 


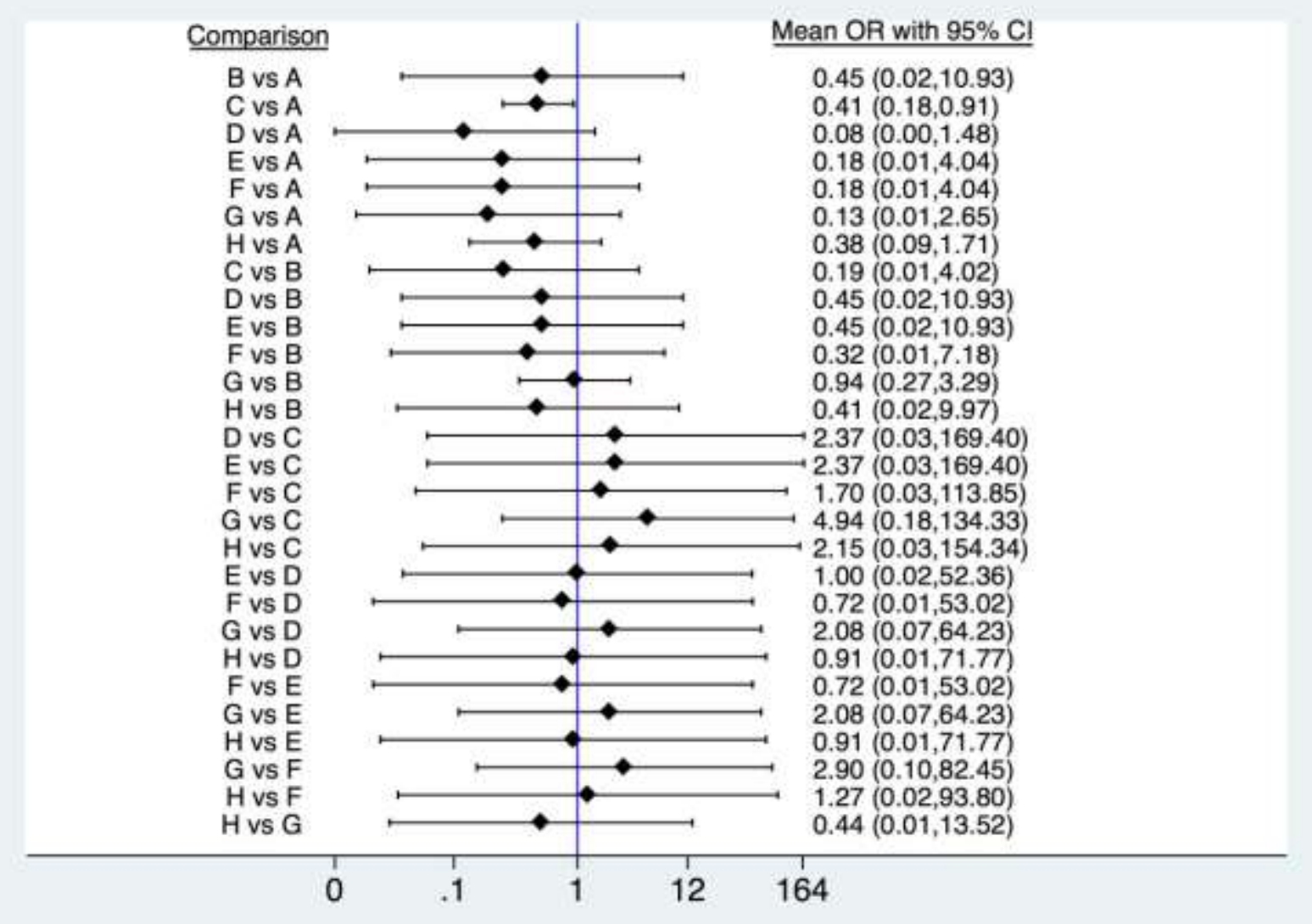

This article is protected by copyright. All rights reserved. 